\title{
Socio-economic and Ethnic Inequalities in Social Capital from the Family among Labour Market Entrants
}

\author{
Pieter-Paul Verhaeghe ${ }^{1,2, *}$, Yaojun $\mathrm{Li}^{2}$ and Bart Van de Putte ${ }^{1}$
}

\begin{abstract}
This study investigates how the socio-economic positions of the parents shape the access to social capital of their children. We examine the influence of three parental socio-economic positions on the access to three job-finding resources from the family among labour market entrants. In addition, we examine how ethnic differences in family social capital are rooted in the unequal socio-economic positions of different ethnic categories. For these purposes, we collected data from 2,176 labour market entrants in Belgium and designed an instrument to measure three types of job-finding resources: labour market information, job information, and encouragement to search for a job. Moreover, we used a multidimensional perspective on social stratification by examining the educational levels, the social class positions, and the employment statuses of the parents. Our results show substantial socio-economic inequalities in family social capital: labour market entrants whose parents are higher educated, employed and/or from the service class have more access to job-finding resources from the family. Moreover, ethnic minorities in Belgium, especially the Turks, Moroccans, and Balkans, have less access to job-finding resources from the family than natives. These findings demonstrate the powerful interplay of parental socio-ethnic influences in shaping inequalities in social capital. Moreover, it is the first crucial step to establish how socio-economic inequalities are reproduced over generations through the functioning of social capital.
\end{abstract}

\section{Introduction}

The occupational attainment process is embedded in social networks. People with larger, more diverse and socio-economically more advantageous networks are more likely to be employed and to have better paid and more prestigious jobs (Lin, 2001). Social network members could help job seekers, for example, through the provision of resources, such as job and labour market information, social influence, and encouragement. These social network resources are considered as social capital in its instrumental tradition (Bourdieu, 1986; Portes, 1998; Völker and Flap, 1999; Lin, 2001; Li, 2010).

Several studies have demonstrated socio-economic inequalities in social capital: people in better socioeconomic positions have more access to social capital
(Erickson, 1996; Völker and Flap, 1999; Lin, 2001). Surprisingly little research has, however, investigated the extent to which inequalities in social capital are the result of different socio-economic family backgrounds. This is surprising, given the importance attached by Goldthorpe (1987: p. 99), the most prominent figure in intergenerational stratification research, to social resources, along with economic and cultural factors, in explaining the relative advantages of people of higher class origins. Examining in detail how the socio-economic positions of the parents shape the access to social capital of their children is the first crucial step to establish how socio-economic inequalities are reproduced over generations through the functioning of social capital. Moreover, it addresses previously raised questions about the causality of the association between socio-economic status and social capital

\footnotetext{
${ }^{1}$ Health and Demographic Research Centre, Department of Sociology, Ghent University, Belgium and ${ }^{2}$ Institute for Social Change, University of Manchester, UK. ${ }^{*}$ Corresponding author. Ghent, Korte Meer 5, 9000 Ghent, Belgium. Email: pieterpaul.verhaeghe@ugent.be
} 
(Mouw, 2002): the socio-economic positions of parents determine the access to social capital of their children and not vice versa.

In addition, insufficient attention has been paid to the economic roots of ethnic inequalities in social capital. Although Wacquant and Wilson (1989) argue that socio-economic inequalities contribute to ethnic differences in social capital, little research has been carried out in this regard.

We aim to contribute to the literature in three ways. First, we examine in detail the extent to which the socio-economic positions of the parents determine the access to family social capital of their children. We differ from previous studies (e.g. Lin and Dumin, 1986; Völker and Flap, 1999; Li, Savage and Warde, 2008; Moerbeek and Flap, 2008) by examining the educational level, the social class position and the employment status of the parents. This multidimensional perspective on social stratification gives us a better understanding of the mechanisms engendering inequalities in social capital. Secondly, we examine the extent to which ethnic inequalities in social capital arise from the unequal socio-economic positions of different ethnic categories. Lastly, as the first study in intergenerational stratification research, we measure inequalities in social capital with the resource generator. This instrument asks about the availability of some specific resources in the social network (Van der Gaag, 2005) and is, consequently, more specific about the nature of social capital inequalities than other, more general, instruments (such as the name- and position-generator methods). For these purposes, we use data from 2,176 labour market entrants in Belgium that contain social capital questions about three types of job-finding resources: labour market information, job information, and encouragement to search for a job.

\section{Theoretical Framework}

\section{Inequalities in Family Social Capital}

We define family social capital as the quantity and quality of resources embedded in the extended family network. According to Bourdieu (1986), the access to social capital depends on the types of capital possessed by network members (in this case family members). Moreover, he sees economic capital at the roots of both cultural and social capital. In other words, the socio-economic positions of family members determine the resources embedded in the family network to which somebody has access.

According to Lin (2001), socio-economic inequalities in the access to social capital can be attributed to two factors. First, historical and institutional processes determine that social groups occupy different socioeconomic positions. Secondly, people have the tendency to interact with others with similar characteristics. People prefer similar others for most kind of activities with, as a consequence, socially homophilous relationships (McPherson, Smith-Lovin and Cook, 2001). Völker, Pinkster and Flap (2008) state that homophilous relationships are not only the result of personal preferences (demand-side), but of geographical and numerical contact opportunities too (supply-side). The combination of these factors produce socio-economic inequalities in social capital: members of deprived social groups are mainly interacting with one another in social networks with poor resources.

\section{Socio-Economic Inequalities in Family Social Capital}

The foregoing suggests that there are inequalities in family social capital because family networks are socioeconomically homophilous. People from disadvantaged groups tend to marry and to associate with other disadvantaged people resulting in family networks with poor resources. Many studies have documented the high levels of educational and class homogamy in marriage patterns (Kalmijn, 1998; Blossfeld, 2009). Moreover, studies on socio-economic positions of siblings suggest a fairly strong degree of similarity too, especially among siblings from more advantaged families (Conley and Glauber, 2008). Although family networks could be heterophilous on a few dimensions (such as gender and age), they tend to be homophilous in socio-economic terms.

For labour market entrants, we expect that the access to family social capital is especially determined by the socio-economic position of their parents. Previous research has shown that the occupational position of the father has positive effects on the access to family social capital of the children (Lin and Dumin, 1986; Völker and Flap, 1999; Moerbeek and Flap, 2008), yet no specific research has been conducted to show which kind of socio-economic factors are more important than others for the access. In this article, we seek to make a contribution in this regard. We distinguish between three socio-economic characteristics of the parents: their employment status, their class position, and their educational level. Distinguishing between these socioeconomic aspects provides a greater insight than available in existing literature into the socio-economic mechanisms producing inequalities in social capital. We also link social and ethnic stratification in this study. 
People who are in paid employment have more opportunities to get information about the labour market and job vacancies than their unemployed or inactive counterparts. Research has shown, for example, that employed job searchers get more job offers through social contacts than unemployed searchers (Blau and Robins, 1990) and that employed people receive more job information during routine conversations than unemployed (Lin and Ao, 2008; McDonald, Lin and Ao, 2009). We expect that the access to family social capital is higher among labour market entrants with employed parents than among those with unemployed or inactive parents.

Moreover, we argue that people from social classes with more powerful resources (in terms of, for example, supervision/authority, skill level, status, and ownership) are in better positions to get information about the labour market or job vacancies than people from lower class positions. First, because of their more advantaged positions they have more opportunities to get information. Secondly, social exchange and rational action theory (Heath, 1976; Goldthorpe, 2007) states that people are more willing to provide information to those in high status positions, because it is more likely that they will get something back in the future and/or because they want to be associated with the prestige of the recipient. Research has indeed shown that people with more supervisory/managerial authority or professional/specialist expertise get more job information during routine conversations (McDonald, Lin and Ao, 2009). In addition, Turner and Marino (1994) have shown class differences in the level of emotional support experienced. Therefore, we expect that the access to family social capital is higher among labour market entrants with parents from the professional and managerial class than among those with parents from the manual working class.

Finally, the educational level of the parents could matter for the access to family social capital too. Highly educated parents have the cultural capital to help their children in developing their soft skills, which are gaining increasing importance in the current post-Fordist labour markets characterized by a high degree of deregulation, job turnover and task flexibility (Burrows and Loader, 1994). Moreover, the information acquired through one's own job could be too specific to be useful. Highly educated parents are more likely to have abstract skills for collecting and processing job and labour market information than lower educated parents. So, we expect that the access to family social capital is higher among labour market entrants with higher educated parents than among those with lower educated parents.

\section{Ethnic Inequalities in Family Social Capital}

The same ideas on socio-economic inequalities in social capital can be applied to ethnic inequalities in family social capital. Because of institutional and historical processes ethnic minorities occupy different, usually much lower, socio-economic positions than the ethnic majority in a country, and because of personal preferences and/or unequal contact opportunities members of deprived ethnic minorities are mainly interacting with one another in social networks with poor resources (Lin, 2001; McPherson, Smith-Lovin and Cook, 2001; Völker, Pinkster and Flap, 2008). European and North-American studies have indeed shown ethnic differences in the socio-economic network composition (Parks-Yancy, 2006; Behtoui, 2007; Li, Savage and Warde, 2008; Völker, Pinkster and Flap, 2008; McDonald, Lin and Ao, 2009). Most of these studies found that ethnic minorities (especially the socio-economically deprived ones) do not differ from natives in the size of their networks, but that they have fewer and poorer network resources.

In this study, we compare the access to social capital from the family between five ethnic categories in Belgium: the Belgians, the North-, West-, and SouthEuropeans, the Moroccans, the Turks, and the Balkans. When we refer to ethnic categories or ethnic inequalities in this article, we only consider the immigrant background of people for analytic purposes and do not make reference to concepts such as ethnic identities, ethnic communities or ethnic boundaries (cf. Simon, 1998; Jacobs et al., 2009). Most of the labour market entrants in our study with a North-, West-, or South-European background were born in Belgium. Most of the Turkish and Moroccan labour market entrants are the grandchildren of the labour migrants who came to Belgium during the golden sixties and stayed afterwards, or the (grand)children of the marriage migrants who arrived in the country during the seventies and later on (Lesthaeghe, 2000). Consequently, they were born and raised in Belgium. In contrast, almost all entrants from the Balkan were born in their country of origin (Perrin, 2008). They arrived in Belgium during their childhood and they reside undocumented in the country or have been regularized.

Research has shown a high degree of socio-economic ethno-stratification in Belgium with respect to employment, unemployment duration, income, job characteristics, and contract type (Verhoeven, 2000; Heath and Cheung, 2007). The highest socio-economic stratum consists of native Belgians. The second stratum is composed of migrants of North-, West-, or SouthEuropean descent. The lowest stratum consists of 
Turkish and Moroccan immigrants and their offspring. The relative position in this socio-economic hierarchy of the recently arrived Balkan migrants is not yet explicitly examined. Research suggests that their socio-economic position is similar to or worse than that of Turks and Moroccans (Geets et al., 2006). Moreover, research has shown a high degree of ethnic homophily in Belgium (Vancluysen et al. 2009). Therefore, we expect that there are ethnic inequalities in family social capital among labour market entrants in Belgium and that these inequalities will follow the socio-economic hierarchy.

Although we expect, as has also been suggested by Wacquant and Wilson (1989), that ethnic inequalities in family social capital would follow the general socioeconomic ethno-stratification in Belgium, surprisingly little empirical research has examined in detail to what extent ethnic inequalities in (family) social capital can be explained by socio-economic factors. In this study, we will explore how ethnic inequalities in family social capital among labour market entrants could be explained by the employment status, class position, and educational level of their parents.

\section{Measuring Family Social Capital}

Much research has assessed socio-economic and ethnic inequalities in social capital. Most of these studies follow one of the two strategies to measure individual social capital in social mobility research. The first strategy investigates how people mobilize personal contacts to find a job instead of using more formal methods (Green, Tigges and Diaz, 1999; Franzen and Hangartner, 2006). Although using this strategy reveals interesting findings, using job contacts as a social capital indicator has some important limitations. First, this method only covers a part of the social network resources. Job contacts could help a job seeker by directly hiring him, putting in a good word with an employer and/or telling him explicitly about job opportunities. These resources are job specific. Network members could, however, assist in ways that are less oriented towards a specific job and that enhance the job-searching capacity of a person in general. Secondly, most personal contact studies examine only people who have found a job (either through personal contacts or through other means) and therefore exclude the unsuccessful job seekers. It is plausible that because unemployed persons have the least social capital, personal contact studies underestimate inequalities in social capital.

The second strategy tries to overcome these limitations by examining inequalities in the social capital capacity (the quantity and quality of resources embedded in social networks) rather than in its manifestations (how network resources are actually triggered in a particular action) (Lin and Ao, 2010). There are mainly three instruments to measure the social capital capacity: name generators, position generators, and resource generators (Lin, 2001; Van der Gaag, 2005; Lin and Erickson, 2008). Name generators list the names of a few network members by asking one or multiple questions (e.g. with who could you discuss important matters?) and subsequently ask about some characteristics of these generated names. Position generators ask respondents whether they know anyone in their social network with an occupation from a list of different jobs usually taken as representative of the occupational structure in a society. The range, position, and accessibility of the accessed occupations are subsequently considered as indicators of the mobilizability of network resources. Finally, resource generators ask directly about the availability of some specific resources in social networks.

Most studies assess social capital inequalities with name generators or position generators (e.g. Lin and Dumin, 1986; Völker and Flap, 1999; Behtoui, 2007; Li, Savage and Warde, 2008; Völker, Pinkster and Flap, 2008; McDonald, Lin and Ao, 2009). These instruments do not clarify, however, how network members help people during their occupational attainment, nor do they shed light on which network resources are helpful to get a (descent) job.

Therefore, this study uses, as the first study in intergenerational stratification research, the resource generator to measure socio-economic and ethnic inequalities in social capital. In contrast to name and position generators, this instrument asks about the availability of some specific resources in the network and is, consequently, more specific about the nature of social capital inequalities. Moreover, it would be odd to examine the association between the family network members' occupational positions and the occupational positions of the parents (like it would be the case when the position generator would have been used). Finally, research has shown that social networks of deprived persons are frequently marked by distrust and a reluctance toward proving job-finding assistance (Domínguez and Watkins, 2003; Smith, 2005). Since resource generators ask on whom respondents could rely for resources, the perceived willingness of networks members to provide resources is incorporated too. The drawback of resource generators is, however, that its results are bounded to the used resource items (Van der Gaag, 2005). Social capital is much broader than the network resources examined in this study.

We study the availability of one job-specific (job information) and two more general network resources 
(job-searching encouragement and labour market information). Research on job contacts has already demonstrated that job information is a helpful network resource for job-seekers (Green, Tigges and Diaz, 1999; Franzen and Hangartner, 2006). In addition, qualitative studies have uncovered at least two more general resources which are helpful for social mobility (Stanton-Salazar, 1997; Domínguez and Watkins, 2003). First, network members could affect peoples' occupational attainment positively by encouraging them during the job search (e.g. strengthening the self-esteem of a job-seeker, or acting as positive role models) or negatively by discouraging them (e.g. via gender expectations on child rearing and household duties that channel people into certain segregated occupations). Secondly, they could provide job seekers with information about the structure and functioning of the labour market in general (e.g. information about how to search for a job and to act during job interviews).

In sum, this study examines to what extent socioeconomic and ethnic inequalities in family social capital (measured by three concrete network resources) among labour market entrants in Belgium arise from the parental socio-economic positions (measured by three socio-economic factors).

\section{Data and Methodology}

\section{Data}

We use data from students in their last years of (part-time) vocational and technical secondary education in two multi-ethnic cities in Belgium. The data were collected during the last two months of their academic year, just before the students were entering the labour market. Data collection in schools is an efficient way in Belgium to get high-quality representative information and to gain access to 'difficult-to-reach' populations like (undocumented) immigrants. Because of compulsory education, all children who reside in the country (including those with a foreign nationality) have to go to school until the age of 18 years. Moreover, schools are not allowed to refuse pupils without a residence permit and the police are not allowed to pick up undocumented migrants.

Nevertheless, since we excluded in our research design students from the general and the art tracks in Belgium, we are analysing social capital inequalities among a specific population of labour market entrants. In contrast to students from the general and the art tracks, most of these people do not study further in higher education before entering the labour market and most of them have working class family backgrounds (which is also reflected in our sample, see Table A in the Supplementary Data at ESR online). Moreover, whereas students from the general and the art tracks are not prepared for a specific profession (except art professions), students from the (part-time) vocational, and technical tracks get more practice-oriented types of education in which they are trained for a specific occupation (e.g. study programmes in hair styling, car mechanics, or sales).

The study used a two-stage sampling design. In the first stage, we selected two cities in Belgium with a high ethnic diversity: Ghent and Mechelen. In the second stage, we contacted the 44 schools in the two cities which were offering the (part-time) vocational and/or technical track in the sixth or seventh grade during the school year 2008-2009. Of these schools 84.1 per cent or 37 schools agreed to participate. Our research team administered a questionnaire among the sixth and seventh graders who were present during the visits. We obtained usable data from 2,176 students (or 83.5 per cent of the population of the schools that agreed to participate).

\section{Dependent Variables}

The key interest of this study is in the access to three social capital resources provided by the family: job information, labour market information, and encouragement to search for a job. We constructed a resource generator with items assessing these three social capital resources. In our choice of resource items, we were guided by the advice of experts on youth unemployment in Belgium and a literature review. The result is a list of 11 resources: 3 items on the availability of labour market information, 4 items on job information, and 4 items on job-searching encouragement (Table 1).

Respondents were asked on whom they could rely for each of these resources in case they would need support. For each resource item multiple response categories could be ticked. The categories were 'I can rely on a family member', 'I can rely on a friend', 'I can rely on a boy/girl-friend', 'I can rely on an acquaintance', and 'I can rely on nobody'. In this study, we focus on the resources available from family members.

We constructed three scales by counting the number of resource items available from family members: labour market information (range: 0-3), job information (range: 0-4), and encouragement during the job search (range: 0-4). We performed non-parametric cumulative Mokken-analysis (Sijtsma and Molenaar, 2002). The three scales have sufficient high reliabilities and homogeneities (Table 1) and are moderately strong correlated with one another $(r=0.63,0.55$, and 0.59$)$. 
Table 1 Resource generator items and scale statistics ${ }^{a}$

Labour market information $(H=0.46$, MS $\rho=0.67)$

$\begin{array}{ll}\text { Giving advice about what is the best way to search for a job } & 0.47\end{array}$

$\begin{array}{lr}\text { Helping to construct a CV } & 0.47\end{array}$

Filling in job administration $\quad 0.44$

Job information $(H=0.53$, MS $\rho=0.79)$

Helping to judge a particular vacancy 0.50

Passing potential vacancies 0.52

Helping to search for vacancies 0.57

Exploring vacancies together 0.55

Encouragement to search for a job $(H=0.60$, MS $\rho=0.80)$

Giving you self-esteem by a chat for a solicitation 0.55

Encouraging you not to give up searching for a job 0.65

Talking about your problems in searching for a job 0.61

Cheering you up when you did not get a particular job 0.59

${ }^{a} H$ : Loevinger Scale Homogeneity Coefficient; MS $\rho$ : Molenaar and Sijtsma reliability statistic; Hi: Item Scalability Coefficients.

\section{Independent Variables}

We measure socio-economic inequalities in the access to social capital, using three socio-economic variables: the highest educational levels of the parents, the employment status of the parents, and the social class position of the parents. ${ }^{1}$

We asked respondents about the highest attained educational level of their parents. Not all respondents were able to tell the exact educational levels of their parents and not all parents have followed Belgian education. We dealt with these problems in three ways. First, we put the age when most people attain a certain educational level between brackets next to each educational title. Secondly, we provided, if necessary, Turkish, Moroccan, and Bulgarian respondents with translated equivalents of the Belgian educational titles. Finally, we constructed for each parent three general educational categories: higher education (having a degree from tertiary education), middle education (having a certificate from higher secondary education), and lower education (having a certificate from lower secondary or primary education, having no diploma at all, or diploma is unknown). After that, we combined the educational levels of both parents in four categories: 'Both higher educated' (15.3 per cent), 'Only one higher educated (17.2 per cent), 'Both or one middle educated' ( 47.5 per cent), and 'Both lower educated' (20.0 per cent).

The employment status of both parents is assessed by asking the respondents about the current main activity of their parents. We distinguished between parents who were (full-time or part-time) employed and parents who were unemployed or inactive on the labour market for longer than a year. This results in a variable with three categories: 'Both parents are employed' (60.8 per cent), 'Only one parent is employed' (27.9 per cent), and 'Both parents are unemployed or inactive' (11.3 per cent).

The parental class positions are measured by asking respondents in detail about the current or last main job of both parents. We recoded the answers to Goldthorpe's (1987) class scheme using the conversion tools of Ganzeboom and his colleagues (1996). For reasons of parsimony, we reduced the 11 classes of Goldthorpe to three categories: the service class (containing higher and lower grades of professional and managerial employees and farm managers), the intermediate class (including routine non-manual workers, small proprietors, foremen, and technicians), and the working class (containing skilled, semiskilled and unskilled workers, farm labourers, and those who have never worked or of whom the occupation is unknown). We further collapsed the class positions of both parents into four categories: 'Both service class' (14.5 per cent), 'Only one service class' (29.1 per cent), 'Both or one intermediate class' (28.9 per cent), and 'Both working class' (26.0 per cent).

The ethnic background is assessed by the countries of birth of the grandmothers. In doing so, we capture the so-called second- and third-generation immigrants in Belgium too. We distinguish between six categories: native Belgians, people from the EU16, Turks, Moroccans, people from the Balkan, and the rest. In our sample, there are 1,450 Belgians (66.6 per cent), 
131 persons from the EU16 (6.0 per cent), 208 Turks (9.6 per cent), 129 Moroccans (5.9 per cent), 59 people from the Balkan (2.7 per cent), and a remaining category of 199 persons (9.2 per cent). ${ }^{2}$ To distinguish between first-generation immigrants and later generation immigrants, we ask whether the respondent was born in Belgium or not. In our sample, 246 labour market entrants (11.3 per cent) were not born in Belgium.

In addition, we control for age, gender and the subjective health status of the respondent. The mean age in our sample is 18.64 years $(s d .=1.31)$ and there are 1,164 men (53.5 per cent) and 1,012 women (46.5 per cent). Respondents were asked to rate their general health. Response categories were: 'very bad', 'bad', 'fair', 'good', and 'very good'. The mean health status in our sample is $3.95(\mathrm{sd} .=0.78)$.

\section{Analytic Strategy}

Socio-economic and ethnic inequalities in the three social capital outcomes are examined using Poisson regression analyses. This technique is appropriate for count outcomes (Long and Freese, 2006), such as the number of available network resources. For each social capital outcome, we run two models. The first model includes the variables on the ethnic background and the three control variables: gender, age, and health. In the second model, we add the educational level, the class position and the employment status of the parents to the variables in the first model. For ease of interpretation, the co-efficients of the Poisson regression models are presented as percent change scores (Long and Freese, 2006). For the categories with a small number of respondents, we would urge the reader to treat the coefficients and their significant levels with caution.

The data of labour market entrants are nested in schools. This violates the assumption of independence of observation with misspecified standard errors as a consequence. We correct for this by controlling for the clustering effects in the analysis with the clustercommand in Stata. This command specifies that the observations are independent across schools, but not necessarily independent within schools. This procedure leads to robust standard errors.

\section{Results}

Table 2 presents the bivariate associations between labour market entrants' access to the three types of family social capital and their ethnic and socio-economic background. First, we see that ethnic inequalities in the availability of social capital from the family follow the socio-economic ethno-stratification in Belgium. Turkish, Moroccan, and especially Balkan minorities have less access to the three job-finding resources than their Belgian counterparts. Entrants from North-, West-, or South-European origins do not differ, however, in their access to family social capital from Belgians.

Secondly, entrants whose parents are lower-educated have less family social capital than those whose parents are higher-educated. Differences in social capital between the other educational categories and the higher-educated category are less pronounced. There are clear class inequalities in the access to family social capital. Labour market entrants from service-class families have the greatest access to social capital, followed by entrants with an intermediate class background. Working class entrants have the least access to social capital from the family. Entrants of whom both parents are currently employed have more access to social capital than entrants with only one parent employed and especially than entrants of whom both parents are unemployed or inactive.

Table 3 shows the results of the regression models on the availability of the three job-finding resources from family members. First, from Models 1, 3, and 5, we can see that there are ethnic inequalities in the availability of job-finding resources from family members after controlling for age, gender, nativity, and health. Whereas people from the EU16 do not have less access to family social capital, Turks, Moroccans, and Balkans have, respectively, 23 per cent, 24 per cent, and 25 per cent less access to labour market information (Model 1), 27 per cent, 27 per cent, and 43 per cent less access to job information (Model 3), and 13 per cent, 16 per cent, and 11 per cent less job-searching encouragement than Belgians (Model 5). The difference in familial encouragement is not significant between Moroccans/Balkans and Belgians, probably because of the small sample size of the two minority ethnic groups, even though the signs are rather clear. In addition, people who were not born in Belgium have 20 per cent less access to labour market information and 15 per cent less access to job-searching encouragement than people who were born in Belgium. Surprisingly, people who were not born in Belgium do not differ significantly in their access to job information than people who were born in Belgium, after controlling for their ethnic background. Overall, ethnic inequalities in family encouragement are less pronounced than those in the access to labour market and job information.

Secondly, looking at the patterns in Models 2, 4, and 6 , we can see clear socio-economic inequalities in the availability of the social network resources, even after taking the ethnic background and the other demographic attributes into account. However, not all three parental 
Table 2 Mean scores of social capital resources by ethnic category and socio-economic background factors

$\begin{array}{ccc}\text { Labour market } & \text { Job } & \text { Encouragement } \\ \text { information } & \text { information } & \text { to search for a job }\end{array}$

\begin{tabular}{|c|c|c|c|}
\hline \multicolumn{4}{|l|}{ Ethnic Category } \\
\hline Belgian (reference) & 2.448 & 2.918 & 2.965 \\
\hline EU16 & 2.295 & $2.705^{+}$ & 2.820 \\
\hline Turkish & $1.809^{* * *}$ & $2.100^{\star * *}$ & $2.520^{* * *}$ \\
\hline Moroccan & $1.824^{\star \star \star *}$ & $2.104^{* * *}$ & $2.447^{\star *}$ \\
\hline Balkan & $1.509^{\star * *}$ & $1.491^{\star * *}$ & $2.321^{\star}$ \\
\hline Rest & $1.739^{* * *}$ & $2.074^{\star * *}$ & $2.495^{\star * *}$ \\
\hline \multicolumn{4}{|l|}{ Educational level parents } \\
\hline Both higher educated (reference) & 2.475 & 2.977 & 3.026 \\
\hline Only one higher educated & 2.348 & 2.839 & 2.894 \\
\hline Both or one middle educated & $2.297^{\star}$ & $2.719^{\star \star}$ & 2.910 \\
\hline Both lower educated/unknown & $1.918^{\star \star *}$ & $2.174^{\star * *}$ & $2.454^{* * *}$ \\
\hline \multicolumn{4}{|l|}{ Social class position parents } \\
\hline Both service class (reference) & 2.515 & 2.966 & 2.985 \\
\hline Only one service class & 2.434 & 2.855 & 2.942 \\
\hline Both or one intermediate class & $2.182^{\star * *}$ & $2.666^{\star *}$ & $2.825^{+}$ \\
\hline Both working class or never worked/unknown & $1.998^{\star * *}$ & $2.303^{\star * *}$ & $2.611^{* * *}$ \\
\hline \multicolumn{4}{|l|}{ Employment status parents } \\
\hline Both employed (reference) & 2.399 & 2.869 & 2.963 \\
\hline Only one employed & $2.142^{\star * *}$ & $2.504^{\star * *}$ & $2.687^{\star *}$ \\
\hline Both inactive or unemployed & $1.826^{\star * *}$ & $2.035^{\star * *}$ & $2.484^{* * *}$ \\
\hline
\end{tabular}

Each of the other categories in a variable is contrasted with the first category (in italics), with the results of significance tests shown. ${ }^{+} P<0.10,{ }^{*} P<0.05$, ${ }^{* *} P<0.01,{ }^{* * *} P<0.001$

socio-economic factors are equally important. The educational attainment of the parents is the most important factor for the access to family social capital. Labour market entrants whose parents are both lower educated have 12 per cent less labour market information, 17 per cent less job information, and 16 per cent less jobsearching encouragement from family members than entrants whose parents are both higher educated. In contrast, we find only marginally significant class differences in the availability of labour market information from relatives. Labour market entrants of whom both parents are from the working class and those with one or both parents from the intermediate class have, respectively, 6 per cent and 7 per cent less access to labour market information than entrants of whom both parents are from the service class. These findings suggest that the deepest class cleavage in family social capital is between service class entrants and non-service class entrants. Moreover, labour market entrants differ in their access to family social capital according to the parental employment status. Entrants of whom both parents are unemployed or inactive on the labour market have 10 per cent less access to labour market information, 15 per cent less job information, and 7 per cent less encouragement to search for a job than entrants of whom both parents are employed.
Finally, as compared with Models 1, 3, and 5, we find that ethnic inequalities in the access to labour market and job information are reduced to a more limited extent after controlling for the personal and socioeconomic factors (Models 2 and 4) and that inequalities in the availability of familial job-searching encouragement are no longer significant (Model 6).

\section{Discussion and Conclusion}

This study investigated the effects of parental socioeconomic positions on the access to three job-finding resources from the family among labour market entrants in Belgium. We studied the availability of one jobspecific (job information) and two more general jobfinding resources (labour market information and job-searching encouragement). Moreover, we examined the extent to which ethnic differences in family social capital are due to the unequal socio-economic positions of different ethnic categories.

First, like Flap and his colleagues (1999, 2008), we found that the parental socio-economic positions determine the access to family social capital. The educational levels of the parents are important for all three types of job-finding resources. Lower educated parents do not 
Table 3 Poisson regression of the availability of social capital resources from the family (per cent change scores)

\section{Labour market Job information Encouragement to information search for a job Model 1 Model 2 Model 3 Model 4 Model 5 Model 6}

\begin{tabular}{|c|c|c|c|c|c|c|}
\hline $\begin{array}{l}\text { Not born in Belgium } \\
\text { (ref. born in Belgium) }\end{array}$ & $-20^{\star \star}$ & $-19^{\star *}$ & -13 & -13 & $-15^{\star}$ & -12 \\
\hline \multicolumn{7}{|l|}{ Ethnic category (ref. Belgian) } \\
\hline EU16 & -5 & -3 & $-6^{+}$ & -4 & -4 & -3 \\
\hline Turkish & $-23^{\star * *}$ & $-15^{\star * *}$ & $-27^{\star * *}$ & $-17^{\star * *}$ & $-13^{\star * *}$ & -7 \\
\hline Moroccan & $-24^{\star * *}$ & $-14^{*}$ & $-27^{* * *}$ & $-16^{*}$ & $-16^{*}$ & -6 \\
\hline Balkan & $-25^{\star *}$ & $-18^{+}$ & $-43^{* * *}$ & $-33^{*}$ & -11 & -6 \\
\hline Rest & $-17^{\star *}$ & $-14^{* *}$ & $-21^{\star *}$ & $-18^{\star}$ & -7 & -6 \\
\hline Female (ref. male) & $10^{\star * *}$ & $12^{* * *}$ & $13^{* * *}$ & $15^{* * *}$ & $13^{* * *}$ & $15^{\star * *}$ \\
\hline Age & $-2^{\star}$ & $-3^{\star *}$ & -2 & -2 & -1 & -1 \\
\hline Subjective health & $3^{*}$ & $3^{*}$ & $4^{\star}$ & $3^{+}$ & $5^{\star * *}$ & $5^{\star *}$ \\
\hline \multicolumn{7}{|l|}{$\begin{array}{l}\text { Educational level parents } \\
\text { (ref. both higher educated) }\end{array}$} \\
\hline Only one higher educated & & -6 & & -6 & & $-8^{*}$ \\
\hline Both or one middle educated & & $-5^{+}$ & & $-8^{*}$ & & $-6^{+}$ \\
\hline Both lower educated/unknown & & $-12^{\star \star \star}$ & & $-17^{\star * *}$ & & $-16^{\star * *}$ \\
\hline \multicolumn{7}{|l|}{$\begin{array}{l}\text { Class position parents } \\
\text { (ref. both service class) }\end{array}$} \\
\hline Only one service class & & 0 & & 1 & & 2 \\
\hline Both or one intermediate class & & $-7^{+}$ & & -1 & & 0 \\
\hline Both working class or never worked/unknown & & $-6^{+}$ & & -3 & & -1 \\
\hline \multicolumn{7}{|l|}{$\begin{array}{l}\text { Employment status parents } \\
\text { (ref. both employed) }\end{array}$} \\
\hline Only one parent employed & & $-4^{*}$ & & $-6^{*}$ & & $-6^{*}$ \\
\hline Both parents inactive or unemployed & & $-10^{*}$ & & $-15^{\star \star}$ & & $-7^{+}$ \\
\hline -2 Log Likelihood & $-3,157.7$ & $-2,975.5$ & $-3,682.9$ & $-3,464.7$ & $-3,729.2$ & $-3,509.8$ \\
\hline
\end{tabular}

${ }^{+} P<0.10,{ }^{*} P<0.05,{ }^{* *} P<0.01,{ }^{* * *} P<0.001$.

have, apparently, the necessary skills to help their children during their job search. In addition, there are class disparities in the access to family social capital. Labour market entrants from service class families have the most access to social capital, followed by entrants from intermediate class families. Working class entrants have the least access to family social capital. The current employment statuses of the parents are essential for the familial access to job-finding resources too. Apparently, parents have to be themselves connected to the labour market to get informed about labour market opportunities and practices for their children. Even after taking into account the educational levels and employment statuses of the parents, the class background is still crucial for the access to labour market information, suggesting that parental class position carries with it social advantages or disadvantages beyond those associated merely with employment status or educational qualification (Wright, 1997; Goldthorpe and McKnight, 2006).

Secondly, consistent with previous research (ParksYancy, 2006; Behtoui, 2007; Li, Savage and Warde, 2008; Völker, Pinkster and Flap, 2008; McDonald, Lin and Ao, 2009), we found ethnic differences in social capital. Ethnic minorities in Belgium, especially Turks, Moroccans, and Balkans, have less access to labour market and job information from the family than natives. Although they have less familial encouragement during their job search too, these differences are less pronounced. Many Turkish, Moroccan, and Balkan families are deprived in Belgium (Verhoeven, 2000; Geets, 2006; Heath and Cheung, 2007). We found that these parental socio-economic positions could explain the limited access to job-searching encouragement of ethnic minorities in Belgium, but only to some extent their unequal access to labour market and job 
information. Especially Turks, Moroccans, and Balkans have lower access to these network resources, which could not be explained by their socio-economic background. This suggests that there are other factors at work at higher levels (such discrimination, contact opportunities, etc.), which should be the subject of future research.

In addition, our results suggest that first generation immigrants have less access to labour market information from the family than second- and third generation-immigrants but not less access to job information. Previous research found that people are more likely to migrate when they could rely on network resources in the country of destination, especially resources from the family (Kalter, 2011). Our research suggests that migrants in Belgium have access to information about job opportunities through family networks, but less access to information about the general labour market (after controlling for ethnic minority penalties). It appears that it takes time for the family to know the Belgian labour market but not to acquire job information. However, the available job information from relatives is probably about jobs in (informal) ethnic niche sectors (such as cleaning and garbage industry, construction industry, and fruit picking), which are characterized by bad working conditions (Verhoeven, 2000).

Moreover, this study used, as the first study in intergenerational stratification research, the resource generator to measure inequalities in social capital. With this instrument we were able to show that the degree of ethnic and socio-economic inequalities in social capital depends on the type of network resources we look at. Therefore, to get a complete picture, future studies should use this instrument in addition to the more common used name and position generators.

However, these findings have to be considered with some caution. First, we measured family social capital with the resource generator. Because this instrument focuses on specific network resources, its results are bounded to the used resource items (Van der Gaag, 2005). There are many other ways in which social capital could help people in finding a (first) job (Völker and Flap, 1999; Lin, 2001; Moerbeek and Flap, 2008). Moreover, we could not exclude the possibility that respondents misperceive the availability of resources in their family network. Secondly, we studied inequalities in social capital among labour market entrants who did not study further in higher education and with mainly working class family backgrounds. Since there are positive associations between education/class and social capital (Erickson, 1996; Lin, 2001), inequalities could be underestimated. Therefore, future research should examine how inequalities in social capital are generated over generations among other populations and with other instruments (such as position generators or name generators).

Notwithstanding these limitations, our study has documented in detail how the socio-economic positions of parents shape the access to social capital of their children. This is, however, only the first step to establish how socio-economic inequalities are reproduced over generations through the functioning of social capital. If further research could establish how these 'inherited' inequalities in social capital contribute to the persisting inequalities on the labour market, then intergenerational stratification research should include social capital mechanisms in their theories and models. In this endeavour, it could be guided by the ideas on social networks of prominent authors such as Bourdieu (1986) and Goldthorpe (1987). Moreover, we only considered the role of family networks in the reproduction of socio-economic inequalities. Given the strength of weak ties for finding poorly paid jobs (Granovetter, 1995) and of strong ties for finding well-paid jobs (Lin, Ensel and Vaughn, 1981), further research needs to examine non-familial ties of both kinds (such as ties with friends, relatives, colleagues, and acquaintances) too.

\section{Supplementary Data}

Supplementary Data are available at ESR online.

\section{Funding}

This research has been financed by the Research Foundation - Flanders (FWO).

\section{Notes}

1 We conducted further analyses where the effects of the socio-economic position of the father and the mother are examined separately. The results of these analyses did not change substantially from these reported in this article (see Tables B and C in the Supplementary Data at ESR online).

2 The EU16-group consists of 23 French, 26 Dutch, 32 Germans, 13 Spaniards, 14 Italians, 5 Greek, 10 people from the United Kingdom, 1 Swiss, 2 Norwegians, 2 Danes, 2 Austrians, and 1 Irish. The Balkan group consists of 17 Bulgarians, 15 
Albanians, 24 people from former Yugoslavia (Kosovo, Bosnia-Herzegovina, Serbia and Montenegro), 2 people from former Czechoslovakia, and 1 Romanian.

\section{References}

Behtoui, A. (2007). The distribution and return of social capital: evidence from Sweden. European Societies, 9, 383-407.

Blau, D. and Robins, P. (1990). Job search outcomes for employed and unemployed. Journal of Political Economy, 98, 637-655.

Blossfeld, H. P. (2009). Educational assortative marriage in comparative perspective. Annual Review of Sociology, 35, 513-530.

Bourdieu, P. (1986). The forms of capital. In Richardson, J. (Ed.), Handbook of Theory and Research for the Sociology of Education. New York: Greenwood.

Burrows, R. and Loader, B. (1994). Towards a Post-Fordist Welfare State? London: Routledge.

Conley, D. and Glauber, R. (2008). All in the family? Family composition, resources, and sibling similarity in socioeconomic status. Research in Social Stratification and Mobility, 26, 297-306.

Domínguez, S. and Watkins, C. (2003). Creating networks for survival and mobility: social capital among African-American and Latin-American low-income mothers. Social Problems, 50, 111-135.

Erickson, B. (1996). Culture, class, and connections. American Journal of Sociology, 102, 217-251.

Flap, H. and Boxman, E. (2000). Getting started: the influence of social capital on the start of the occupational career. In Lin, N., Cook, K. and Burt, R. (Eds.), Social Capital: Theory and Research. New York: DeGruyter.

Franzen, A. and Hangartner, D. (2006). Social networks and labour market outcomes: the non-monetary benefits of social capital. European Sociological Review, 22, 353-368.

Ganzeboom, H. and Treiman, D. (1996). Internationally comparable measures of occupational status for the 1988 international standard classification of occupations. Social Science Research, 25, 201-239.

Geets, J. et al. (2006). Nieuwe Migranten en de Arbeidsmarkt. Leuven: HIVA.

Goldthorpe, J. (1987). Social Mobility and Class Structure in Modern Britain. Oxford: Clarendon Press.

Goldthorpe, J. (2007). On Sociology. California: Stanford University Press.
Goldthorpe, J. and McKnight, A. (2006). The economic basis of social class. In Morgan, S., Grusky, D. and Fields, G. (Eds.), Mobility and Inequality: Frontiers of Research in Sociology and Economics. California: Stanford University Press.

Granovetter, M. (1995). Getting a Job. A Study of Contacts and Careers. Chicago: University Press.

Green, G., Tigges, L. and Diaz, D. (1999). Racial and ethnic differences in job-search strategies in Atlanta, Boston, and Los Angeles. Social Science Quarterly, 80, 263-278.

Heath, A. (1976). Rational Choice \& Social Exchange: A Critique of Exchange Theory. Cambridge: Cambridge University Press.

Heath, A. and Cheung, S. (2007). Unequal chances. Ethnic minorities in western labour markets. Oxford: Oxford University Press.

Jacobs, D. et al. (2009). The challenge of measuring immigrant origin and immigration-related ethnicity in Europe. Journal of International Migration \& Integration, 10, 67-88.

Kalmijn, M. (1998). Intermarriage and homogamy: causes, patterns, trends. Annual Review of Sociology, 24, 395-421.

Kalter, F. (2011). Social capital and the dynamics of temporary labour migration from Poland to Germany. European Sociological Review, 27, 555-569.

Lesthaeghe, R. (2000). Communities and Generations: Turkish and Moroccan Populations in Belgium. Brussels: VUB Press.

Li, Y. (2010). Measuring social capital: formal and informal activism, its socio-demographic determinants and socio-political impacts. In Bulmer, M. et al. (Eds.) Social Measurement Through Social Surveys: An Applied Approach. Ashgate Publishing.

Li, Y., Savage, M. and Warde, A. (2008). Social mobility and social capital in contemporary Britain. British Journal of Sociology, 59, 391-411.

Lin, N. (2001). Social Capital: A Theory of Social Structure and Action. Cambridge: University Press.

Lin, N. and Ao, D. (2008). The invisible hand of social capital: an exploratory study. In Lin, N. and Erickson, B. (Eds.), Social Capital. An International Research Program. Oxford: University Press.

Lin, N. and Ao, D. (2010). The long hand of social capital. Impact of acquisition of job information through routine social exchanges on position obtaining. Journal of Xi'an Jiaotong University, 30, 74-88.

Lin, N. and Dumin, M. (1986). Access to occupations through social ties. Social Networks, 8, 365-385.

Lin, N., Ensel, W. and Vaughn, J. (1981). Social resources and the strength of ties: structural factors 
in occupational attainment. American Sociological Review, 46, 393-405.

Long, S. and Freese, J. (2006). Regression Models for Categorical Dependent Variables using Stata. Texas: Stata Corporation.

McDonald, S., Lin, N. and Ao, D. (2009). Networks of opportunity: gender, race, and job leads. Social Problems, 56, 385-402.

McPherson, M., Smith-Lovin, L. and Cook, J. (2001). Birds of a feather: homophily in social networks. Annual Review of Sociology, 27, 415-444.

Moerbeek, H. and Flap, H. (2008). Social resources and their effect on occupational attainment through the life course. In Lin, N. and Erickson, B. (Eds.), Social Capital. An International Research Program. Oxford: University Press.

Mouw, T. (2002). Racial differences in the effects of job contacts: conflicting evidence from cross-sectional and longitudinal data. Social Science Research, 31, 511-538.

Parks-Yancy, R. (2006). The effects of social group membership and social capital resources on careers. Journal of Black Studies, 36, 515-545.

Perrin, N. (2008). Asielzoekers, Vluchtelingen en Staatslozen in België. Brussels: CNTR.

Portes, A. (1998). Social capital: its origins and applications in modern sociology. Annual Review of Sociology, 24, 1-24.

Sijtsma, K. and Molenaar, I. (2002). Introduction to Nonparametric Item Response Theory. London: Sage.

Simon, P. (1998). Nationalité et origine dans la statistique française. Les catégories ambiguës. Population, 3, 541-568.
Smith, S. (2005). "Don't put my name on it": social capital activation and job-finding assistance among Black urban poor. American Journal of Sociology, 111, $1-57$.

Stanton-Salazar, R. (1997). A social capital framework for understanding the socialization of racial minority children and youths. Harvard Educational Review, 67, $1-40$.

Turner, J. and Marino, F. (1994). Social support and social structure: a descriptive epidemiology. Journal of Health and Social Behavior, 35, 193-212.

Van der Gaag, M. (2005). Measurement of Individual Social Capital. Rijksuniversiteit Groningen.

Vancluysen, K., Van Craen, M. and Ackaert, J. (2009). Gekleurde Steden. Autochtonen en Allochtonen Over Samenleven. Brugge: Vandenbroele.

Verhoeven, H. (2000). De Vreemde eend in de Bijt. Leuven: WAV.

Völker, B. and Flap, H. (1999). Getting ahead in the GDR: social capital and status attainment under Communism. Acta Sociologica, 42, 17-34.

Völker, B., Pinkster, F. and Flap, H. (2008). Inequality in social capital between migrants and natives in the Netherlands. Kölner Zeitschrift für Soziologie und Sozial Psychologie, 48 (Sonderheft), 325-350.

Wacquant, L. and Wilson, W. (1989). The cost of racial and class exclusion in the inner city. Annals of the American Academy of Political and Social Science, 501, $8-25$.

Wright, E. (1997). Class Counts. Cambridge: Cambridge University Press. 